\title{
ИЗУЧЕНИЕ ЦИТОКИНОВОГО ПРОФИЛЯ ПРИ ПРИМЕНЕНИИ ИМУНОФАНА У БОЛЬНЫХ САХАРНЫМ ДИАБЕТОМ 2 ТИПА С ИНФЕКЦИЕЙ МОЧЕВЫХ ПУТЕЙ
}

\author{
'Насыртдинова А.Д., ${ }^{2}$ Моругова Т.В., ${ }^{2}$ Алибаева Г.Ф. \\ 'ГОУ ВПО «Башкирский государственный университет» Минздрава России, Уфра \\ гГБУЗ РБ Городская больница № 3, Стерлитамак
}

ЦЕЛЬ: оценить иммуномодулирующие действия имунофана (Иф) у больных инфекцией мочевых путей (ИМП) на фоне сахарного диабета 2 типа (СД2).

МАТЕРИАЛЫ И МЕТОДЫ: в Исследование было включено 106 человек, из них 26 - больные СД2, 30-больные ИМП, 25- больные СД 2 типа с ИМП, 25-больные СД2 с ИМП получавшие имунофан (50 мкг 1 раз в сутки, 10 дней), и 35 практически здоровых человек. Содержание цитокинов IL 4, IL 6, TNF- a, TNF- a определяли в день обращения, а у пациентов СД2 с ИМП- и через 2,4 и 8 недель лечения. Статистический анализ данных проводили с применением пакета программ «Statistika 8.0». Результаты представлен в виде медианы (Ме) и квартилей (25\%-75\%), минимального и максимального значений.

РЕЗУЛЬТАТЫ: установлено, у больных СД2 было повышение в сыворотке крови изученных цитокинов (по сравнению с группой здоровых лиц), уровень IL 4 был повышен в 3 раза ( $p=0,00006)$, уровень IL 6 -

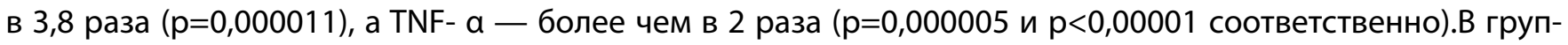
пе СД2 +ИМП происходил цитокиновый дисбаланс, IL 4 в 3,5-4 раза превышал аналогичный показатель в группе здоровых пациентов в 1,5 раза, в группе СД2 ( $p=0,0041$ и $\mathrm{P}=0,00005$ соответственно) и ИМП ( $p=0,0048$ и $p=0,00006$ соответственно), уровень IL 4 снижался к 3-му и 4-му визиту. Показатель IL 6 у пациентов СД2 +ИМП не отличался с СД2 и у пациентов с ИМП без СД2, превышая аналогичный показатель у здоровых в 4-4,5 раза на все сроки наблюдения. Содержание TNF- а в крови больных СД 2 типа с ИМП в 1-й визите превышал показатель у здоровых в 1,8 раза ( $<<0,00001)$, а к 4-й визиту, несмотря на проводимую терапию, в 2,4 раза ( $<<0,00001)$, у больных СД 2 типа +ИМП во все сроки не отличался от пациентов с СД2 без ИМП. К окончанию наблюдений следует отметить, что уровень TNF- а превышал аналогичный показатель у пациентов с ИМП без СД2 в 1,73 раза ( $\mathrm{p}=0,0007)$. Уровень провоспалительных цитокинов IL 4, IL 6, TNF- а у больных СД2+ИМП на фоне базистной терапии ИМП, существенно отягощают течение ИМП, включение имунофана в терапию ИМП у больных СД2 проявилось увеличением уровня IL 4 в процессе лечения (2-й. 3-й визиты) ИМП с последующим его снижением (4-й визит), уровень IL 4 у пациентов получавших Иф, был выше аналогичного показателя у пациетов ИМП без СД2 на 2-й и 3-й визиты - в 1,3 раза. Применение Иф обеспечивало увеличение уровня IL 4 на 40\% по сравнению СД2 без ИМП до 4-й недели наблюдения.

\section{ВЫводы.}

1. У больных СД 2 типа показало повышение уровня провоспалительных цитокинов (IL 6, TNF-a).

2. С ИМП сохраняется высокий уровень провоспалительных цитокинов на фоне проводимой терапии.

3. Применение имунофана у больных СД2 с ИМП снижает уровень провоспалительных цитокинов (IL-6, TNF- a) и повышает уровень IL-4.

КЛЮЧЕВЫЕ СЛОВА: сахарный диабет; инфекция мочевых путей; имунофан. 